\title{
O TRABALHO COM A ADAPTAÇÃO LITERÁRIA NA ESCOLA
}

\author{
WORKING WITH LITERARY ADAPTATION AT SCHOOL
}

Eliane Soares de LIMA

Universidade de São Paulo/ USP

li.soli@usp.br

Resumo: A modernização da sociedade, das tecnologias e, a partir daí, a ampliação do acesso às novas mídias têm colocado ao ensino na educação básica demandas cada vez maiores para o desenvolvimento das habilidades de leitura, análise e escrita. O diálogo entre o verbal e o visual - e, de maneira mais ampla, entre as diversas linguagens - passa a ocupar nesse domínio um lugar de destaque, como comprovam as orientações da Base Nacional Comum Curricular, a BNCC. A exigência agora é extrapolar o conteúdo dos textos, lançando luz também ao seu plano de expressão, com textos correspondentes à diversidade das práticas comunicativas contemporâneas. Isso coloca ao professor o desafio não só da seleção diversificada dos textos, mas, principalmente, da forma com a qual eles serão trabalhados em sala de aula, uma vez que os discursos neles enunciados são manifestados por variadas situações de enunciação, cada qual com suas especificidades discursivo-textuais. Assim, tomando o trabalho com as adaptações literárias na escola como uma estratégia didática eficaz para realização efetiva de práticas de multiletramentos, interessa-nos mostrar as contribuições que a Semiótica Discursiva pode oferecer ao enfrentamento desses desafios.

Palavras-chave: ensino; multiletramentos; tradução intersemiótica; HQ; Semiótica Discursiva.

Abstract: The modernization of society, of technologies and, as a result, the widening of access to new media have been creating increasing demands on basic education for the development of reading and writing skills. The dialogue between verbal and visual and, more broadly, between the various languages - now occupies a prominent place in this field, as evidenced by the guidelines of the Common National Curricular Base, the BNCC. Today's requirement is to go beyond the content of the texts, also shedding light on their expression plane, with texts corresponding to the wide range of contemporary communicative practices. This poses the teacher the challenge not only of the diversified selection of texts, but mainly of the way in which they will be worked on in class, since the discourses enunciated in them are manifested by various situations of enunciation, each one with its discursive and textual specificities. Thus, taking the work with literary adaptations in school as an effective didactic strategy for achieving multiliteracies practices, we would like to examine the contributions that Discursive Semiotics can offer to the confrontation of these challenges.

Keywords: teaching; multiliteracies; intersemiotic translation; comics; Discursive Semiotics. 


\section{Introdução}

As adaptações, conforme assinala Hutcheon (2013), estão em todos os lugares hoje em dia: nas telas da televisão e do cinema, nas páginas dos romances e dos quadrinhos, nos palcos do teatro, em canções, musicais, games etc. Dessa forma, a primeira vantagem didático-pedagógica do trabalho com as adaptações literárias na escola, para além da proximidade, em alguns casos, do universo cultural do aluno e da possibilidade de ampliá-lo, está na variedade de gêneros e mídias com que se pode trabalhar; a segunda, na oportunidade de chamar a atenção dos estudantes para outros níveis de análise que podem participar da construção do sentido, como as características físicas do objeto-suporte, as práticas de leitura e interação que ele assim determina, as estratégias de acomodação que é preciso assumir quando ele envolve mais de uma prática, e mesmo as formas de vida que se inauguram ou recriam a partir daí ${ }^{1}$.

Desse modo, assumindo que o trabalho com as adaptações literárias na escola, em cotejo com a obra de partida, pode ser um recurso didático produtivo para lidar com o desafio da análise semiótica prescrita pela BNCC, para a qual coloca-se a exigência de ir além da exploração do conteúdo discursivo dos diferentes tipos de texto para examinar junto com os alunos também as especificidades do plano de expressão, da materialidade da(s) linguagem(ns) de manifestação em causa, nosso objetivo aqui é o de mostrar as contribuições que algumas das proposições da Semiótica discursiva podem oferecer. Para isso, dividiremos a argumentação desta nossa proposta em quatro partes: (i) uma discussão inicial sobre o potencial do estudo das adaptações literárias na escola, de modo geral, e das HQs, em especial, para o desenvolvimento das competências de leitura, análise e escrita de textos de tipo variado, tendo como foco a prática de análise semiótica na escola; (ii) a apresentação de noções-chave da proposta teórico-metodológica da Semiótica Discursiva para o exame do plano de conteúdo e expressão dos textos; (iii) um exemplo breve e prático de aplicação a partir de uma página da adaptação para HQ do romance Dom Casmurro, de Machado de Assis, com sugestões de encaminhamento didático; e, por fim, (iv) algumas considerações finais sobre o desafio da exigência dos multiletramentos e, a partir dele, da análise semiótica na escola.

A escolha por exemplificar a discussão com uma adaptação literária feita em quadrinhos se justifica pela presença considerável do gênero no Programa Nacional Biblioteca da Escola (PNBE)², de 2006 a 2014, cujo objetivo era compor acervos em bibliotecas escolares públicas para democratizar o acesso ao livro e, assim, incentivar à leitura. Ademais, a opção explica-se ainda pela presença abundante de gêneros próximos - a charge, a tira e o cartum - nos livros didáticos e nas avaliações de larga escala (SAEB, PISA, ENEM). Um outro ponto de interesse, e talvez o mais importante, é o fato de, em geral, ser o conteúdo discursivo desse tipo de texto o que é mais comumente trabalhado em sala de aula, deixando de lado justamente a exploração do plano da expressão e o incentivo a sua compreensão. O romance machadiano, por sua vez, foi selecionado por

1. Estamos pensando aqui na ideia dos diferentes níveis de pertinência da análise semiótica conforme propostos por Fontanille (2008).

2. Substituído atualmente pelo PNLD Literário, que faz parte do Programa Nacional do Livro e do Material Didático desde 2018. 
seu reconhecimento, nacional e internacional, como um dos grandes clássicos da literatura brasileira, e, por isso mesmo, costumeiramente trabalhado na escola.

\section{Do resultado ao processo de adaptação}

Adaptar, em sua definição dicionarizada, é "modificar (algo) para que se acomode, se ajuste ou se adeque (a uma nova situação, um determinado fim, um meio de comunicação etc.)" (HOUAISS, 2009, s. p.). Isso explica ter como termos sinônimos: aclimar, acomodar, afeiçoar, assentar, encaixar. Essa breve definição, bem como a rede de significados próximos que ela evoca, já mostra que é no cotejo com a obra de partida que a exploração da adaptação literária em sala de aula terá mais produtividade didática, viabilizando o desenvolvimento de habilidades de leitura, análise e escrita mais amplas. Mas, para que isso de fato possa ocorrer, é necessário que a exploração dos textos (de partida e de chegada) privilegie o processo de transposição mais do que o produto final, as ações em jogo para além dos resultados, as estratégias retóricas envolvidas para convencer e fazer sentir, por fim, a tensão entre as limitações impostas pelas coerções de determinada linguagem e, ao mesmo tempo, as novas possibilidades oferecidas pelo novo plano da expressão selecionado. Este é o tipo de trabalho que precisa ser realizado pelo professor para que os alunos possam, progressiva e ativamente, de acordo com os desafios cognitivos próprios a sua faixa etária, perceber a complexidade da ação de adaptar uma obra.

O fenômeno da adaptação pode ser definido, segundo Hutcheon (2013), a partir de três perspectivas distintas, porém inter-relacionadas, que apontam, por sua vez, bons caminhos de exploração, como critérios de análise para o trabalho na escola. A primeira diz respeito à transposição declarada de um universo textual a outro (gênero, mídia, contexto sociocultural, linguagem etc.), sendo a discussão sobre as particularidades formais de cada um dos universos textuais o que deve ser privilegiado, suas diferenças e semelhanças e as implicações decorrentes. Já a segunda se refere ao ato criativo e interpretativo de apropriação/recuperação da obra de partida, que pode ser pensado também do ponto de vista do que Mancini (2020, p. 17) chama de (re)criação do projeto enunciativo, esse "“espírito da obra' de partida que molda suas características mais marcantes", como "um conjunto de estratégias postas em prática pelo sujeito da enunciação para orquestrar as categorias semióticas em um todo de sentido" (p. 27). A identificação desse projeto enunciativo seria, pois, o ponto de partida para a análise. A terceira perspectiva remete à experiência da obra como adaptação, como uma forma de "intertextualidade extensiva" (HUTCHEON, 2013, p. 28); daí importar, nesse momento, a compreensão do diálogo menos ou mais direto entre o texto de partida e o de chegada. Nesta última forma de abordagem possível, entra a problemática da identidade mais marcada ou mais tênue entre as obras e, consequentemente, a questão da fidelidade, ou dos graus de proximidade, entre os textos em questão, que não deve, no entanto, "ser o critério de julgamento ou o foco de análise" (HUTCHEON, 2013, p. 28); afinal, "a persistência temática e narrativa junta-se à variação material [...], e assim as adaptações nunca são simplesmente reproduções" (p. 25).

É a inter-relação entre essas três perspectivas mencionadas por Hutcheon (2013), mais do que o privilégio de uma ou outra, o que deve ser explorado em sala de aula com os alunos, porque, de modo geral, o mais interessante é levá-los a perceberem que "o 
que está em jogo é a recriação de um projeto enunciativo em outro" (MANCINI, 2020, p. 31), uma vez que:

reconstruir o projeto enunciativo de partida sob as novas coerções impostas pela concepção da obra de chegada (coerções que podem ser de diversas ordens, como diferenças semânticas e sintáticas de uma nova língua, mobilizações sensoriais diversas em linguagens diferentes, nova cultura, perfil do leitor etc.) faz com que o tradutor [ou adaptador] se coloque na posição de um Janus que deve tirar da sua interpretação da obra de partida as escolhas que darão forma à obra de chegada. (MANCINI, 2020, p. 17)

Uma possibilidade de trabalho em sala seria, pois, colocar em primeiro plano a relação intertextual entre a obra de partida e a de chegada para alimentar a discussão e levar os alunos a perceber o que exatamente foi transposto, o que cada adaptador escolheu manter ou recriar no processo de adaptação e, sobretudo, de que maneira, "o que tem a ver não só com o conteúdo da obra em si, que pode desenvolver/criar novas ideias em relação à obra-fonte, mas também com o novo formato, que exigirá outra postura em relação a sua leitura" (RODRIGUES, 2014, p. 106).

Esse encaminhamento didático, além de promover um maior interesse pela leitura dos clássicos eles mesmos, incitará tanto a curiosidade investigativa e o senso crítico dos alunos, sua capacidade de avaliação estética, quanto o desenvolvimento das habilidades necessárias a esse tipo de leitura e análise, sendo que, a partir delas, também a prática da produção de adaptações pode ser estimulada, em exercícios de condensação ou expansão do conteúdo adaptado a outros planos da expressão, de operações cognitivas e discursivas de ordens diversas, seja no sentido das dificuldades impostas pelas coerções próprias a cada tipo textual, seja no das novas possibilidades de construção do sentido oferecidas.

O uso das adaptações literárias na escola não pode, portanto, restringir-se à ideia de facilitação da leitura, de simplificação que exige menos do leitor, devendo, ao contrário, ser ressaltada, desde cedo, como um processo criativo de interpretação e (re-)criação cultural mais amplo, de ressignificação.

\section{O caso da adaptação literária em HQs}

A presença das histórias em quadrinhos na escola, sobretudo como material didático, nem sempre foi vista com bons olhos (JUNIOR, 2004; VERGUEIRO, RAMOS, 2009). Somente a partir da publicação dos PCNs (1997-98), que incluía em suas orientações ao processo de ensino-aprendizagem de Língua Portuguesa o uso de HQs, o gênero foi ganhando mais espaço. Essa inclusão oficial teve ainda mais impulso a partir de 2006, quando o Programa Nacional Biblioteca da Escola (PNBE) passou a se interessar também por obras em quadrinhos, com preferência para as adaptações literárias. Até 2014, quando o Programa foi encerrado e substituído, em 2018, pelo PNLD literário, tinham sido compradas 126 obras em quadrinhos, entre elas 57 adaptações (YAMAGUTI, 2018). Esse interesse se justifica, conforme assinalam Vergueiro e Ramos (2009), pela ideia de que as adaptações literárias em quadrinhos poderiam servir como facilitadoras da leitura dos clássicos, além de se apresentarem num formato mais atrativo ao gosto dos jovens. 
De toda maneira, embora as HQs tenham, de fato, ocupado o seu espaço entre os objetos de conhecimento a serem estudados na escola, a exploração desse tipo de material se mantém, na maioria dos casos, restrito ao exame do conteúdo discursivo, muitas vezes usado apenas como corpus de atividades gramaticais (SILVA, 2016), desconsiderando-se, nas atividades de análise e interpretação, o exame das propriedades semióticas dos quadrinhos, de seu plano de expressão textual propriamente dito, das características específicas da sua linguagem sincrética, multimodal, com o visual em diálogo direto com o verbal. É bem verdade que a preparação teórica e metodológica dos professores para lidar com esse tipo de exploração é ainda bastante ausente nos cursos de formação, o que dificulta esse tipo de trabalho com os textos manifestados por outras linguagens além da verbal.

Um ponto de partida importante no uso das adaptações literárias em quadrinhos na escola é, então, a consciência de que ler uma HQ não é o mesmo que ler um romance, um conto ou um poema. Diferentes formas de dizer aí se caracterizam e, por conseguinte, distintos modos de engajamento, de experenciar o conteúdo discursivo. Acrescentaríamos ainda que, em cada caso, configura-se uma prática de leitura diferenciada, demandando, por isso mesmo, habilidades outras de leitura e análise. Segundo Hutcheon (2013, p. 49), "contar uma história em palavras, seja oralmente ou no papel, nunca é o mesmo que mostrála visual ou auditivamente em quaisquer das várias mídias performativas disponíveis", uma vez que "cada modo, assim como cada mídia, tem sua própria especificidade, se não sua própria essência" (p. 49, grifo da autora).

É, portanto, a dinâmica da narrativa quadrinística, as peculiaridades da sua linguagem de manifestação, da construção dos sentidos, o que deve ser destacado ao se trabalhar com a adaptação literária em HQ, mesmo porque, "a chave para entender a mensagem de um determinado meio de comunicação é compreender seu processo de produção e funcionamento" (VERGUEIRO, 2018, p. 7). Embora no caso da adaptação para os quadrinhos mantenha-se a mesma mídia da obra de partida, o material impresso, é fato que as propriedades formais dos gêneros são bastante diversas:

A leitura imagética pode ter uma complexidade ímpar, e a linguagem da
narrativa gráfica, que coloca essas imagens em sequência, trabalhando com
a dinâmica do espaço na página, com o tratamento visual das palavras,
com a função emotiva da cor e do traço e com metáforas visuais, pode
ser ainda mais singular. (RODRIGUES, 2014, p. 115)

Para a prática de leitura de textos visuais, é importante, ademais, ressaltar as duas faces da imagem: como representação visual de uma figura do mundo natural, mas também como plano de expressão visual que manifesta esse conteúdo discursivo por meio das cores, das formas e da organização no espaço considerado. Uma imagem tem tanto um conteúdo discursivo, que ela representa, quanto uma dimensão de expressão textual que o explicita visualmente.

No caso do plano de expressão das HQs, diferente da obra em prosa, a linguagem de manifestação do conteúdo é sincrética (multimodal), com o verbal e o visual ajustando-se mutuamente num todo de significação para criar uma narrativa verbovisual. A esse respeito Barbieri (2017, p. 214, grifo do autor) insiste: “uma característica própria da linguagem dos 
quadrinhos é que o texto verbal forme parte efetiva da imagem [representada visualmente], e não faz sentido considerar texto e imagem como objetos separados". Ele explica:

A ideia geralmente mais difundida da linguagem dos quadrinhos é que se trata da justaposição de uma linguagem "das palavras" e uma linguagem "das imagens". [...] as coisas não são tão simples: mesmo que se tratasse de uma aparente "simples" justaposição, o efeito global resultaria não das palavras por si mesmas nem das imagens por si mesmas, mas de suas relações. (BARBIERI, 2017, p. 177, grifo do autor)

Uma outra característica importante das histórias em quadrinhos é que elas "têm como traço principal ser uma forma de comunicação baseada na fragmentação da linearidade narrativa por parte do autor, linearidade essa que deve ser recomposta no momento da produção de sentido pelo leitor" (VERGUEIRO, 2018, p. 6-7). Trata-se, nos termos de Postema (2018), de uma arte sequencial, com imagens na maioria das vezes restritas por uma moldura (quadros, requadros ou vinhetas) e justapostas, de modo a criar suas próprias lacunas (sarjetas ou calhas), isto é, os lapsos de tempo entre os diferentes momentos da sequência, os quais, ao mesmo tempo, ancoram e relacionam as cenas, podendo substituir ações, trocas de cenário, ou mesmo a passagem temporal. Daí Groensteen (2015, p. 55) dizer que "cada novo quadro precipita a narrativa e, simultaneamente, a contém"; ele acrescenta: "O requadro é o agente dessa dupla manobra de progressão/retenção" (p. 55).

A forma das HQs é, como se pode ver, construída com sequências de imagens que trabalham juntas para compor a dimensão narrativa, com os requadros devendo ser considerados "um em relação aos outros, e não apenas por si mesmos" (POSTEMA, 2018, p. 58). Enquanto o narrado é explicitado em cada moldura, nos recortes das diferentes cenas mostradas verbovisualmente, a narração, mesmo quando não explicitada pelos recordatórios ${ }^{3}$, institui-se na combinação sequencial delas. Assim, "qualquer narrativa quadrinizada, por mais simples ou breve que seja, exige do leitor que este esteja (pre)disposto a reelaborar os fragmentos que recebe" (VERGUEIRO, 2018, p. 7).

Outro aspecto igualmente importante, segundo destaca Postema (2018, p. 20-21), é que:

as sequências de quadros não são o único instrumento que carrega o sentido dos códigos temporal e narrativo; o próprio formato e os modos de separação dos quadros trazem, também, significado. Os marcadores paratextuais, como os contornos dos quadros, o tamanho dos espaços entre e em volta dos quadros, a localização dos quadros nas páginas (mise en page ou layout) e a cor do fundo da página, são todos significantes.

Entra aí a problemática do layout das páginas, "criado por molduras e sarjetas, que separam os quadros individuais, criando estrutura e ordem” (POSTEMA, 2018, p. 22) e instituindo "as condições para a leitura" (p. 58). Isso explica porque Groensteen (2004, p. 44) define a HQ em si como uma "poética do espaço". De fato, o que funda a linguagem da história em quadrinhos, como vimos, é precisamente a multiplicidade de imagens em situação de co-presença no seio de um multiquadro, todas elas criteriosamente organizadas.

3. Texto verbal usado para manifestar a enunciação enunciada de um narrador. 
Os constituintes formais da expressão dessa narrativa ao mesmo tempo contada e mostrada, por um discurso condensado e ágil no qual atuam, simultaneamente, a sequencialidade da leitura e as lacunas que é preciso preencher, funcionam juntos na construção do(s) sentido(s) e têm função bem marcada dentro do gênero. No caso específico das adaptações, são todos elementos básicos que se colocam "como força de coerção que molda as escolhas do adaptador da literatura para quadrinhos, que se vê impelido seja a fazer sínteses, seja a privilegiar partes específicas da obra de partida a ser adaptada" (MANCINI, 2019, p. 106-107). Desse modo, "síntese ou triagem de partes passam a ser as duas estratégias principais que definem um gesto a priori do adaptador da literatura para quadrinhos" (MANCINI, 2019, p. 107), para respeitar "a coerção de agilidade da linguagem dos quadrinhos" (p. 108).

Os pontos aqui mencionados mostram, por fim, que a maneira mais produtiva de trabalhar com as HQs em sala de aula, sobretudo no caso das adaptações literárias, é destacando os aspectos que as separam das outras formas de comunicação e, mais especificamente, de outras formas narrativas, especificando-as como gênero.

\section{Contribuições da Semiótica Discursiva à prática de análise semiótica na escola}

A Semiótica Discursiva se apresenta como uma teoria geral da significação preocupada em identificar, compreender e descrever o processo e as condições de produção do sentido nos textos quaisquer que sejam, verbais e/ou não-verbais. Mais do que o que é dito, interessa, dentro dessa perspectiva, o modo de dizer que o sobredetermina. O texto é concebido como estrutura, como construção regida por diferentes níveis de organização discursivotextual, nos quais operam variados mecanismos e procedimentos de discursivização e de textualização, ambos produtos da enunciação.

Essa distinção entre os procedimentos está relacionada à diferenciação, metodológica, feita entre as noções de discurso e texto. O primeiro é da ordem do plano de conteúdo, objeto linguístico, histórico e ideológico, responsável pela "mensagem transmitida"; é o resultado dos procedimentos de discursivização assumidos por um enunciador. O segundo é da ordem do plano da expressão, da linguagem (verbal e/ou não-verbal) que manifesta o conteúdo discursivo por meio de procedimentos de textualização. Trata-se de uma discriminação metodológica e operatória assumida pela teoria (FIORIN, 2012). Desse modo, um discurso manifestado pela linguagem verbal, por exemplo, vai ter, no processo de textualização, que se adequar à imposição da linearidade, da organização consecutiva, sequencial de seus elementos constitutivos, definindo para a sua apreensão também esse modo de funcionamento, diferente do que acontecerá com um discurso manifestado pela linguagem visual, cuja dinâmica é da ordem da simultaneidade, da concomitância na apresentação dos constituintes.

Os procedimentos de discursivização são, pois, aqueles que respondem pela organização do plano de conteúdo discursivo, anteriormente à sua manifestação por uma (ou mais) linguagem(ns). Eles se distribuem nos diferentes níveis de abstração do chamado percurso gerativo do sentido, um simulacro metodológico que permite "uma reformulação 
menos intuitiva das estruturas e das operações postas em jogo" (GREIMAS; COURTÉS, 2008, p. 143). Esse percurso gerativo do sentido vai da organização discursiva mais simples e abstrata à mais complexa e concreta, organizando o processo de geração da significação em três níveis que se relacionam hierarquicamente, cada um deles podendo ser examinado a partir de categorias de análise próprias, ainda que a significação do texto dependa da interrelação entre eles e da textualização em determinada linguagem, conforme procuraremos mostrar no exemplo do próximo tópico ${ }^{4}$.

Essa gramática discursiva que se configura a partir desse percurso gerativo do sentido deve servir ao exame e à compreensão do modo variável (porque específico a cada produção textual) de dizer, de combinar e articular as categorias invariáveis que compõem cada um dos três níveis. Assim, no nível discursivo, que é o mais concreto e complexo, o da organização de superfície, com o qual temos contato de maneira mais direta no momento da leitura (e da análise), interessam os modos de projeção das categorias de pessoa, espaço e tempo, bem como as figuras e temas selecionados pelo enunciador para garantir o enriquecimento e a maior especificidade semântica do discurso. Além disso, é nesse recobrimento temático e figurativo das estruturas mais abstratas dos outros níveis que as determinações sócio-históricas e ideológicas dos discursos se mostram de forma mais cabal (FIORIN, 2002). No nível narrativo, é a sucessão de estados (de conjunção ou disjunção), as transformações realizadas por um sujeito em relação com um dado objetovalor (qualquer que seja, concreto ou abstrato, animado ou inanimado), o que se deve examinar, assim como a existência de uma sequência de estabelecimentos e rupturas de contratos (fiduciários) entre sujeitos (destinador e destinatário). Em outras palavras:

A semiótica parte dessa visão espetacular da sintaxe e propõe duas concepções complementares de narrativa: narrativa como mudança de estados, operado pelo fazer transformador de um sujeito que age no e sobre o mundo em busca dos valores investidos nos objetos; narrativa como sucessão de estabelecimentos e de rupturas de contratos entre um destinador e um destinatário, de que decorrem a comunicação e os conflitos entre sujeitos e a circulação de objetos. As estruturas narrativas simulam, por conseguinte, tanto a história do homem em busca de valores ou à procura de sentido quanto a dos contratos e dos conflitos que marcam os relacionamentos humanos. (BARROS, 1990, p. 16)

No nivel fundamental, o mais geral e abstrato, o mais profundo, são os universos semânticos que estão na base de todo o desenvolvimento discursivo do texto o que deve ser buscado. Trata-se de termos que se relacionam por oposição, em uma diferença que se institui a partir de um traço comum englobante, como vida vs. morte, natureza vs. cultura, feminino vs. masculino, por exemplo. Esses dois polos de sustentação do plano de conteúdo formam a estrutura semântica elementar do enunciado, dinamizada pelas operações de negação e afirmação desses contrários, as quais simulam, metodologicamente, a sucessividade narrativa, permitindo compreender a sua organização mínima, lógico-conceptual. Cada um dos dois universos semânticos mobilizados é, ademais, qualificado axiologicamente pelo

4. Para uma melhor compreensão da proposta teórico-metodológica da Semiótica Discursiva a partir de um exemplo de aplicação mais didático, sugerimos também a leitura de Lima (2009). 
enunciador como sendo eufórico (positivo) e disfórico (negativo); definição que regerá, por sua vez, no nível narrativo, as relações entre sujeito e objeto-valor.

No que se refere aos procedimentos de textualização - mais próximos ao que espera a BNCC como prática de análise semiótica - são dois os conceitos que mais importam: o de sincretismo e o de semissimbolismo. A noção de sincretismo na perspectiva da Semiótica Discursiva é, conforme explica Teixeira (2004), herdeira direta da definição de neutralização fonológica proposta por Hjelmslev (2013 [1943]), que chama a atenção para o resultado da superposição entre duas (ou mais) categorias diferentes reunidas em uma única grandeza semiótica ocasionando o apagamento da oposição, de modo que a diferença transforma-se em identidade. Nesse sentido, nos textos que mobilizam mais de uma linguagem para a manifestação do conteúdo discursivo, a autonomia de cada materialidade se neutraliza para formar um todo de sentido único e ampliado, porque, uma vez organizadas e combinadas, as materialidades da linguagem sincrética passam a operar ao modo de um continuum, o qual pode ir desde a convergência total entre as diferentes linguagens selecionadas (com menor ou maior grau de integração) a uma possível divergência, por contraposição. Pode-se, então, falar em uma solidariedade por: conexão, quando houver uma vinculação de sentidos por acréscimo entre as linguagens em questão; redundância, apontando para uma autonomia aparente do sentido de cada uma delas; síntese, na retomada por resumo entre os sentidos produzidos pelos diferentes segmentos; ou mesmo em uma combinação por discordância, com destaque ao contraste entre os sentidos de cada um deles (TEIXEIRA, 2004).

O estudo dos procedimentos de textualização de um texto sincrético tem, portanto, a tarefa de descrever e explicar as estratégias de construção do efeito de unidade produzido, justamente para evitar a ideia equivocada de uma soma das partes e a desconsideração da significação global que se alcança através do arranjo textual, do acúmulo e da combinação das qualidades matéricas na construção do sentido final. Por isso mesmo, um outro aspecto a ser observado na análise de textos sincréticos diz respeito, conforme destaca Gomes (2009), às formas de estruturação das materialidades envolvidas, que podem se dar tanto por justaposição, quando o efeito de unidade parece se construir por adição (caso das trilhas sonoras de filmes, novelas etc., ou das imagens que passam a compor um videoclipe), quanto por sobreposição, com efeito de unidade mais explícito (como ocorre nas HQs, nas peças de teatro, nas canções pela junção de letra e melodia).

Também a noção de semissimbolismo se associa a concepções hjelmslevianas, desta vez à ideia de sistemas simbólicos e semióticos, em contraposição ao que se chamou de sistemas semissibólicos. Nos textos em que atua uma articulação semissimbólica entre o plano da expressão textual e o plano do conteúdo discursivo, a(s) linguagem(ns) de manifestação mobilizada(s), conforme procuraremos mostrar na análise a seguir, não apenas materializa(m) o discurso em questão, mas recria(m) seus sentidos por meio da exploração dos recursos expressivos por ela(s) oferecidos, adiciona $(\mathrm{m})$ a eles uma carga semântica "suplementar", mais sensorial, que intensifica a experiência sensível de apreensão da significação global.

O interesse didático de todas essas noções aqui apresentadas, e mesmo da distinção entre procedimentos de discursivização e textualização, está na oferta de elementos 
operacionais eficazes à orientação e reflexão a ser feita em sala de aula para fomentar a discussão sobre o uso das linguagens quaisquer que sejam, das consequências retóricas das escolhas assumidas por um enunciador no momento da produção de certos efeitos de sentido, ou, melhor dizendo, sobre os "usos expressivos" que se pode fazer - para usar o termo adotado pela BNCC ao se referir à análise semiótica.

É importante ressaltar, todavia, que o que estamos propondo aqui não é a transposição direta da proposta teórico-metodológica da Semiótica Discursiva para sala de aula, e sim a sua utilização como instrumento de orientação didático-pedagógica para a condução de atividades "epilinguageiras", com vistas ao aprofundamento das habilidades de leitura, análise e escrita por parte dos alunos (LIMA, 2019, 2021b). Não são, portanto, as noções teóricas em si, pensadas no quadro epistemológico da Semiótica Discursiva como níveis de organização, o que tem valor didático, mas a possibilidade que oferecem ao professor, enquanto princípios norteadores, de instituir caminhos para a observação da organização textual, da função das unidades constituintes de uma dada totalidade significante qualquer que seja.

\section{Um exemplo}

Para demonstrar o valor operacional das proposições teórico-metodológicas discutidas anteriormente, passaremos agora à análise de uma das páginas iniciais da adaptação em quadrinhos de Rodrigo Rosa (arte) e Ivan Jaf (roteiro) do romance Dom Casmurro, de Machado de Assis, publicada em 2012 pela editora Ática, na coleção "Clássicos Brasileiros em HQ", e selecionada pelo PNBE em 2013. A limitação da exploração a uma única página deve-se à complexidade de sua composição, uma vez que nela, como em geral nas páginas de quadrinhos com mesmo layout, "muita informação é oferecida ao mesmo tempo, em várias camadas, como também toma corpo em um enunciado construído com muita demanda de catálises" (MANCINI, 2019, p. 104), com isso "os elementos - de conteúdo, de expressão ou ambos - são apresentados de modo acelerado, o que demanda um esforço de desaceleração no momento da leitura para que o leitor possa concatenar os fatos de maneira a construir todos os seus liames de coesão" (p. 104).

Ainda sobre esse efeito de aceleração - presente na página selecionada - ao qual se relaciona a necessidade de desaceleração para o processamento inteligível do conteúdo discursivo manifestado, Barbieri (2017, p. 216) salienta que, "sem dúvida, uma vinheta grande e complexa requer um tempo de leitura maior que uma vinheta de dimensões e complexidade normais em relação ao contexto da história", até porque esse tempo de leitura maior pode corresponder "à sua maior importância no relato e não à sua maior duração relatada; trata-se de um acento narrativo, um modo de destacar o que se conta" (BARBIERI, 2017, p. 216, grifos do autor). De fato, a página em questão concentra o "tom" da adaptação como um todo.

5. Sugestão de ampliação da noção de atividade epilinguística proposta por Franchi (1991), para englobar também o trabalho com textos não-verbais. 
Para começar, iremos nos debruçar no exame da passagem da obra original a que remete a página da HQ, o capítulo II de Dom Casmurro, intitulado "Do livro" (ASSIS, 2008 [1899], p. 7-9):

\section{$[\ldots]$}

Vivo só, com um criado. A casa em que moro é própria; fi-la construir de propósito, levado de um desejo tão particular que me vexa imprimi-lo, mas vá lá. Um dia, há bastantes anos, lembrou-me reproduzir no Engenho Novo a casa em que me criei na antiga Rua de Mata-cavalos, dando-lhe o mesmo aspecto e economia daquela outra, que desapareceu. Construtor e pintor entenderam bem as indicações que lhes fiz: é o mesmo prédio assobradado, três janelas de frente, varanda ao fundo, as mesmas alcovas e salas. Na principal destas, a pintura do teto e das paredes é mais ou menos igual, umas grinaldas de flores miúdas e grandes pássaros que as tomam nos bicos, de espaço a espaço. Nos quatro cantos do teto as figuras das estações, e ao centro das paredes os medalhões de César, Augusto, Nero e Massinissa, com os nomes por baixo... [...] O mais é também análogo e parecido. [...]

O meu fim evidente era atar as duas pontas da vida, e restaurar na velhice a adolescência. Pois, senhor, não consegui recompor o que foi nem o que fui. Em tudo, se o rosto é igual, a fisionomia é diferente. Se só me faltassem os outros, vá um homem consola-se mais ou menos das pessoas que perde; mais falto eu mesmo, e esta lacuna é tudo. [...] Os amigos que me restam são de data recente; todos os antigos foram estudar a geologia dos campos-santos. [...]

Ora, como tudo cansa, esta monotonia acabou por exaurir-me também. Quis variar, e lembrou-me escrever um livro. [...]

Fiquei tão alegre com esta ideia, que ainda agora me treme a pena na mão. Sim, Nero, Augusto, Massinissa, e tu, grande César, que me incitas a fazer meus comentários, agradeço-vos o conselho, e vou deitar ao papel as reminiscências que me vierem vindo. Deste modo, viverei o que vivi [...]

Em termos de procedimentos de discursivização, algumas características logo chamam a atenção. Trata-se de uma narrativa em primeira pessoa, de cunho memorialístico, autobiográfico; o que já aponta para o desdobramento dos "eus" da história, os quais entrelaçam a debreagem enunciativa, do eu-aqui-agora da enunciação enunciada, à debreagem enunciva, do ele(eu)-lá-então do passado enunciado e, então, rememorado, revivido. O trecho selecionado é rico em descrições e divagações, em figuras e temas que remetem a um estado marcado pela tensão entre passado e presente, saudade da juventude eufórica e constatação da velhice disfórica, entre o convívio alegre de outrora e a triste solidão de agora.

Desse início, que se apresenta como um "prefácio" da história, no qual o narradorpersonagem se detém a explicar os motivos que o levaram a escrevê-la, surge um sujeito melancólico, em busca de si mesmo, da compreensão do que já foi, da vida vivida "de uma 
ponta a outra". Assim se institui o percurso narrativo principal do romance, com um sujeito que quer, por meio da escrita, reviver o passado eufórico e, desse modo, compreender as razões do presente disfórico. O enunciado se constrói nesse entrelaçamento do já sabido da enunciação enunciada (a narração) com os fatos "se fazendo" no enunciado enunciado (o narrado), garantindo o envolvimento afetivo do enunciatário, que reviverá com o narradorpersonagem as emoções desse percurso; e isso sob o contrato firmado de que a narrativa é, mais ou menos, como essa que agora se conta - "vou deitar ao papel as reminiscências que me vierem vindo" (grifo nosso). A subjetividade do eu que conta a história é, dessa forma, colocada como alicerce do narrado.

Essas oposições de base que fundam a arquitetura discursiva do capítulo - e, podemos dizer, do romance inteiro - não se apresentam, todavia, de maneira óbvia, mas emaranhadas no devir discursivo, de modo que só o olhar mais atento às figuras e aos temas que as especificam permite defini-las com clareza em termos de presente vs. passado, juventude vs. velhice, vida vs. morte, alegria vs. tristeza.

A respeito dos procedimentos de textualização, a linguagem de manifestação em causa é a verbal escrita, que destaca a linearidade como principal coerção do significante. $O$ conteúdo veiculado se constitui progressivamente, palavra por palavra, bem como a imagem mental a partir dele criada, sem que haja uma exploração mais evidente da materialidade da linguagem verbal para complementar a experiência de apreensão. Salvo engano, ela tem apenas a função utilitária, prática, de textualizar o conteúdo discursivo, que concentra todo o trabalho de criação.

Vejamos agora como tudo isso vai aparecer na página da adaptação (Figura 1). 
Figura 1: Página da versão em HQ de Dom Casmurro (roteiro de Ivan Jaf e Ilustração de Rodrigo Rosa)

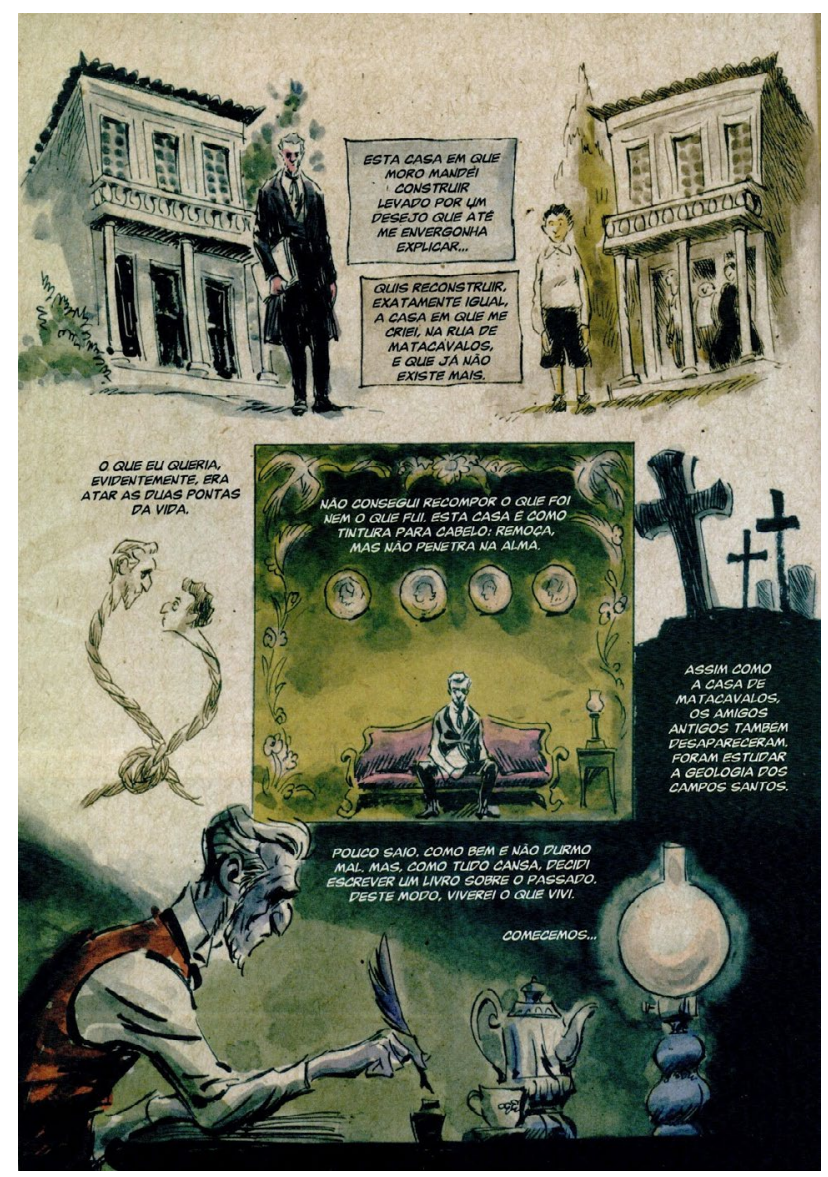

Fonte: ROSA; JAF, 2012, p. 6.

Logo de início se destaca o layout carregado da página, uma série de informações apresentadas simultaneamente, com uma única divisão em quadro. Mesmo assim, as figuras parecem distribuídas em diferentes planos de leitura, dado o paralelismo de sua organização no espaço da página. Na parte superior, chama a atenção a contraposição das formas e das cores, assim como das figuras discursivas que elas manifestam através do traço cartunizado do enunciador: a do homem adulto na casa vazia e acinzentada, ao lado do jovem na casa povoada, em tom amarelado; no meio deles aparecem os recordatórios (fala do narrador), cujo conteúdo discursivo remete igualmente à tensão entre presente disfórico vs. passado eufórico, e ao desejo de reviver de alguma forma este último. A relação entre visual e verbal aí se dá por conexão, uma vez que os conteúdos de cada componente complementam o sentido um do outro.

Na sequência, vem o que parece ser o segundo plano de leitura da página, e que mantém a sequencialidade narrativa, pelos recordatórios de cada uma das três cenas: a explicação do desejo que o moveu à tentativa de reconstrução da casa (cena 1); a frustração da sanção negativa a esse fazer (cena 2); e a constatação do estado atual de solidão (cena 3). 
Figura 2: Sequência de cenas 1, 2 e 3, respectivamente.

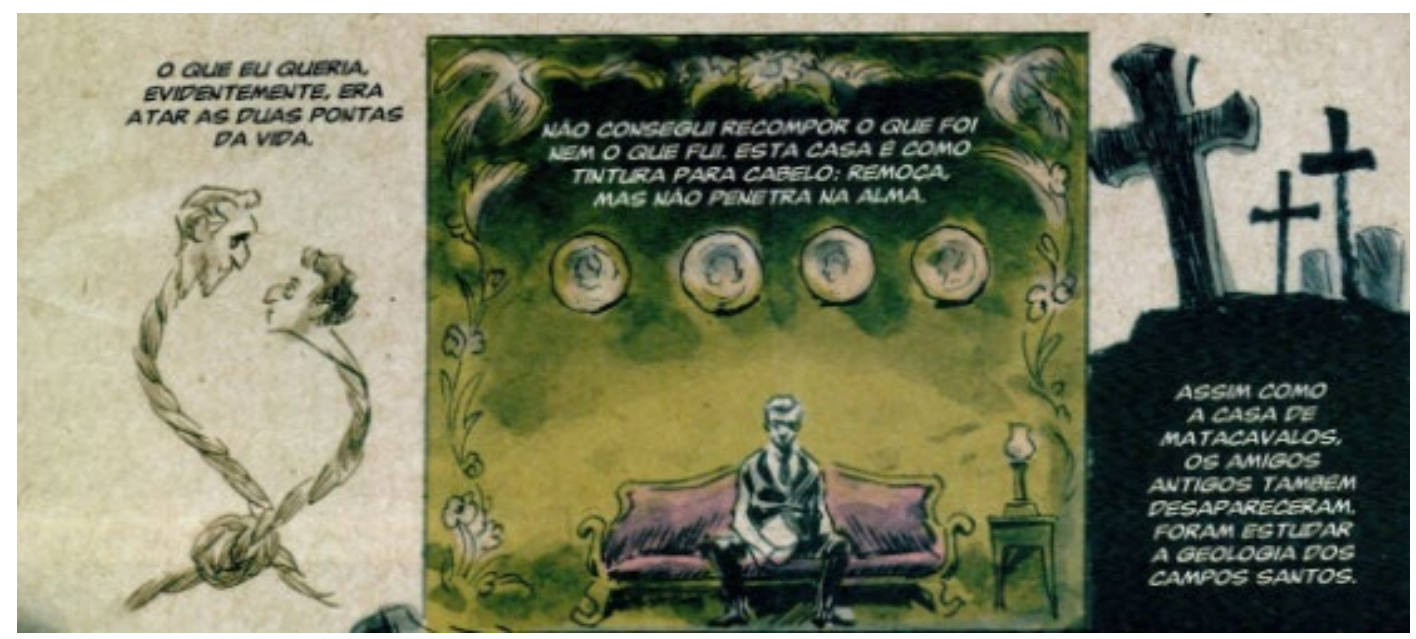

Fonte: ROSA; JAF, 2012, p. 6.

Cada um desses conteúdos ganha mais corpo e sentido a partir da imagem que os retoma, mas a interação entre verbal e visual agora varia entre: uma aparente redundância, no caso da primeira cena, em que o visual apenas retoma o já dito pelo componente verbal, iconizando-o (cena 1), sem acrescentar novas informações; uma relação por conexão na segunda cena, na qual, enquanto o componente verbal faz a sanção da ação realizada, o visual não só a reitera como também manifesta a descrição detalhada da sala principal da casa (cena 2); e, por fim, na última cena desse segundo plano de leitura uma articulação por síntese, com o verbal expandindo o sentido dado visualmente pela figura do cemitério (cena 3 ).

O terceiro e último plano de leitura da página traz à cena o narrador-personagem, responsável pela voz que ressoa nos recordatórios. É a enunciação enunciada da qual se desdobrará toda a narrativa, com o foco narrativo do romance mantido na HQ, uma vez que o discurso apresentado também como memória se faz por meio um eu-aqui-agora da enunciação enunciada que, na parte inferior da página, (re-)constrói a sua história, com o ele(eu)-lá-então do passado enunciado, na parte superior. O contraste entre claro e escuro na página garante a divisão bem marcada desses dois universos debreados, enfatizando a separação entre o eu do presente e os do passado. O próprio formato da linha divisória que se institui na divisão dos dois domínios temporais parece remeter a um balão de fala, ou de pensamento, faz pensar em um apêndice (aponta na direção do responsável pelo discurso), culminando, de fato, na cabeça daquele que escreve e, portanto, narra a história. O contraste cromático entre claro e escuro reforça ainda a ideia do passado eufórico e do presente disfórico, respectivamente.

Há, dessa forma, para além do efeito de aceleração causado, no primeiro contato com a página da $\mathrm{HQ}$, pela apresentação simultânea das várias figuras, um controle, por parte do enunciador, do acesso ao conteúdo. Embora o layout se componha de apenas um requadro, com o restante das figuras em volta dele, a sequencialidade própria ao gênero se mantém, mas por outros recursos de organização da expressão textual: a disposição combinada das figuras na página, com o paralelismo entre elas, bem como o contraste das formas e das cores. Além disso, esse único requadro interno do layout (cena 2), colocado 
no centro da página, parece funcionar como uma espécie de eixo, criando o efeito de circularidade, que articula os três planos de leitura e, assim, retoma a ideia de ciclo natural da vida, da existência que vai da vida jovem à morte na velhice. Garante-se, com isso, a dinâmica de leitura ágil, mas guiada e ainda sequencial, bem ao gosto das HQs, conforme é observado por Mancini (2019) em seu estudo sobre a adaptação em quadrinhos de Grande Sertão Veredas.

Um outro aspecto das estratégias assumidas para a adaptação do capítulo é o da escolha do enunciador-adaptador (roteiro e arte) de privilegiar o procedimento de síntese mais do que o de triagem. O conteúdo discursivo veiculado pela articulação entre verbal e visual, em diferentes formas de inter-relação, retoma trechos idênticos da obra original, os quais, mesmo triados, ainda garantem a representação do todo. Com isso, o enunciador aumenta o efeito de identidade entre as obras, logo, o de maior fidelidade. Vale enfatizar, no entanto, que, conforme assinalado anteriormente, a problemática da fidelidade não deve ser tomada como critério de avaliação das adaptações, nem como foco da análise.

Percebe-se, de modo geral, que, diferente da obra original, o plano de expressão sincrético da HQ não apenas manifesta o conteúdo discursivo, mas o recria em toda a sua passionalidade. Por meio da exploração dos recursos formais do componente visual (categorias cromática, eidética e topológica), o enunciador traduz visualmente as oposições semânticas de base da obra original e, assim, exacerba a dimensão sensível do narrado, fazendo com que o enunciatário não apenas sinta a tensão, mas a veja, porque agora explicitada. Ele traz para a superfície textual - sobretudo, pelo contraste cromático - a dimensão figural das oposições subjacentes ao conteúdo discursivo do romance, recrudescendo a tensão que as alimenta.

O mesmo acontece com a representação do discurso memorialístico enfatizado visualmente, ao longo de toda $\mathrm{HQ}$, pelo predomínio do uso da cor sépia e do fundo das páginas em tom amarelado, de papel envelhecido, ou reciclado. Cria-se o efeito de esmaecimento e, com ele, o de tempos de outrora. Essa estratégia de textualização se soma aos elementos que tornam mais evidente a força passional do narrado, a dimensão afetiva do conteúdo.

Todas essas observações mostram que o trabalho de cotejo entre texto de partida e texto final adaptado, ou vice-versa, como duas situações distintas de uso da(s) linguagem(ns), é mesmo uma estratégia didática profícua, levando os alunos a identificar modos variados de construção da significação e a compreender que, para além dos sentidos criados pelo conteúdo discursivo dos enunciados, também a materialidade da linguagem de manifestação faz parte do sentido global gerado.

Conforme temos insistido em publicações anteriores (LIMA, 2019, 2021b), perguntas bem formuladas e recorrentes nos exercícios de análise oral e coletiva dos textos, feitas pelo professor para orientação da atenção dos alunos ao que importa em cada momento, são um bom recurso didático-pedagógico, porque estimulam a reflexão e a curiosidade, o debate, além de discipliná-los a sempre notarem os usos e as funções dos constituintes discursivo-textuais, bem como o caráter sistemático das construções. Além disso, o trabalho de leitura e análise conduzido por perguntas facilita tanto o controle do grau de dificuldade e abstração que se pode exigir em cada etapa de escolaridade, quanto a progressão das 
habilidades que podem ir aos poucos se complexificando, inclusive com a inserção da metalinguagem para os anos finais.

Não se trata, portanto, de formular perguntas cuja resposta já está dada na superfície do texto e que, por isso mesmo, não representam nenhum desafio intelectual aos alunos, mas de perguntas que possam direcionar o olhar deles à arquitetura subjacente, a uma intencionalidade discursivo-textual que se pode depreender por meio de uma análise semiótica minuciosa, porque atenta aos constituintes dos diferentes níveis de análise. Isso importa porque esse trabalho de explicitação guiada das formas variadas de o texto construir o(s) sentido(s) tanto facilita o refinamento das habilidades de leitura e análise, quanto instiga os alunos a operar com e sobre a(s) linguagem(ns) da mesma maneira, isto é, a empregar em suas próprias práticas de escrita aquilo que descobriram como possibilidade de uso. Daí a importância da seleção de obras capazes de favorecer esse tipo de exploração.

\section{Considerações finais}

Na BNCC, a exigência da análise semiótica, associada à análise linguística, torna a tarefa da formação de leitores - críticos e autônomos - mais ampla, uma vez que "as linguagens [...] passam a ter status próprios de objetos de conhecimento escolar" (BRASIL, 2017, p. 63), de modo que "os estudantes se apropriem das especificidades de cada linguagem, sem perder a visão do todo no qual elas estão inseridas" (ibid.). É aí que o trabalho com as adaptações literárias, como recurso didático, sustenta-se muito bem, unindo demandas de ensino a possibilidades de aprendizagem, justamente por facilitar o encargo de levar os alunos a ler as outras linguagens, reconhecendo suas particularidades formais, a experienciar outras formas de fruição estética. Ademais, tem-se, dessa maneira, a implicação prática de poder colocar em contato e estabelecer diálogos pertinentes entre objetos culturais menos e mais valorizados, menos e mais próximos da realidade cotidiana dos alunos, tal como deve ser para um aprendizado percebido por eles mesmos como significativo. Para Rojo (2009, p. 115), “cabe [...] à escola potencializar o diálogo multicultural, trazendo para dentro de seus muros não somente a cultura valorizada, dominante, canônica, mas também as culturas locais e populares e a cultura de massa, para torná-las vozes de um diálogo, objetos de estudo e de crítica".

Ainda que isso represente apenas uma parte das questões envolvidas na problemática dos multiletramentos escolares, podemos dizer que, como um importante primeiro passo nessa direção, a exploração das adaptações literárias como recurso didático, se bem conduzida, pode, sim, auxiliar significativamente no compromisso primeiro do professor de língua (materna ou estrangeira) de tornar o aluno um leitor autônomo e crítico, ao mesmo tempo, um produtor competente de textos variados. Com esse tipo de trabalho, não apenas se reconhece a variedade de práticas culturais associadas à leitura e à escrita em diferentes contextos, mas também a ensina produtivamente, organizando a abordagem de tal multiplicidade.

O breve exame comparativo que fizemos entre o capítulo de Dom Casmurro e a sua adaptação na página da HQ de mesmo nome procurou mostrar que as categorias de análise propostas pela Semiótica discursiva permitem a elaboração de perguntas fixas, que terão, todavia, respostas variadas para cada texto estudado, chamando a atenção dos alunos para: 
os universos semânticos de base que organizam todo o conteúdo discursivo e a sua valoração axiológica (eufórica ou disfórica); a estrutura narrativa subjacente ao que é dito e a sua organização em cada caso; a construção do ponto de vista a partir do qual se tem acesso às informações, e os efeitos de subjetividade e/ou objetividade instituídos, bem como a sua função persuasiva; as figuras escolhidas (ou não) para concretizar discursivamente certos temas e o posicionamento ideológico que então se pode depreender; a ancoragem sóciohistórico e/ou cultural menos ou mais evidente a que elas apontam; a possível presença de diálogos intertextuais e o modo de sua retomada no texto examinado; o uso da materialidade da linguagem de manifestação na criação de sentidos (exploração estética de recursos gramaticais, sons, cores, formas, distribuição no espaço, densidade gráfica, movimento, ritmo etc.) relacionados à textualização do discurso; os tipos de relação estabelecidas entre a manifestação textual e o plano de conteúdo discursivo, entre as diferentes linguagens mobilizadas e mesmo a sua participação no gerenciamento do acesso, inteligível e sensível, por parte do enunciatário, ao que é dito; as estratégias argumentativas e persuasivas que se podem identificar; enfim, sobre tudo aquilo que possa levar o aluno a perceber o texto como construção, como lugar de concretização de expressões e leituras da realidade circundante, como espaço retórico por excelência.

\section{REFERÊNCIAS}

ASSIS, M. Dom Casmurro. São Paulo: Folha de S. Paulo (Coleção Folha Grandes Escritores Brasileiros), 2008 [1899].

BARBIERI, D. As linguagens dos quadrinhos. São Paulo: Peirópolis, 2017.

BARROS, D. L. P. Teoria semiótica do texto. São Paulo: Editora Ática, 1990.

BRASIL. Parâmetros curriculares nacionais: terceiro e quarto ciclos do Ensino Fundamental: Língua Portuguesa/Secretaria de Educação Fundamental. Brasília: MEC/SEF, 1998.

BRASIL. Base Nacional Comum Curricular (versão final homologada). Brasília: Ministério da Educação, Secretaria de Educação Básica, 2017.

BRASIL. Lei de Diretrizes e Bases da Educação Nacional, LDB. 9394/1996.

BRASIL. Lei de Diretrizes e Bases da Educação Nacional, LDB. 5692/1971.

DIONISIO, A. P.; VASCONCELOS, L. J. Multimodalidade, gênero textual e leitura. In: BUZEN, C.; MENDONÇA, M. (orgs.) Múltiplas linguagens para o ensino médio. São Paulo: Parábola, 2013. p. 19-42.

FIORIN, J. L. Da necessidade de distinção entre texto e discurso. In: BRAIT, Beth; SOUZAe-SILVA, Maria Cecília (orgs.). Texto ou discurso? São Paulo: Contexto, 2012. p. 145-163.

FIORIN, J. L. Em busca do sentido. São Paulo: Contexto, 2008

FIORIN, J. L. Linguística e pedagogia da leitura. Scripta, vol. 7, n. 14. Belo Horizonte, 2004. p. 107-117.

FIORIN, J. L. Linguagem e ideologia. São Paulo: Ática, 2002.

FONTANILLE, J. Pratiques sémiotiques. Paris : PUF, 2008. 
FRANCHI, C. Criatividade e gramática. São Paulo: Secretaria da Educação, Coordenadoria de Estudos e Normas Pedagógicas, 1991.

GREIMAS, A. J.; COURTÉS, J. Dicionário de Semiótica. Trad.Alceu Dias Lima et al. São Paulo: Contexto, 2008.

GROENSTEEN, T. O sistema dos quadrinhos. Trad. Érico Assis e Francisca Ysabelle Manríquez Reyes. Nova Iguaçu: Marsupial Editora, 2015.

GROENSTEEN, T. Histórias em quadrinhos: essa desconhecida arte popular. Trad. Henrique Magalhães. João Pessoa: Marca da Fantasia, 2004.

GOMES, R. S. O sincretismo no jornal. In: OLIVEIRA, A. C.; TEIXEIRA, L. (orgs.). Linguagens na comunicação: desenvolvimentos de semiótica sincrética. São Paulo: Estação das Letras e Cores, 2009. p. 215-245.

HUTCHEON, L. Uma teoria da adaptação. Trad. André Cechinel. Florianópolis: UFSC, 2013.

HJELMSLEV, L. (1943) Prolegômenos a uma teoria da linguagem. São Paulo: Perspectiva, 2013.

JAF, I.; ROSA, R. Dom Casmurro. São Paulo: Ática, 2016.

JUNIOR, G. A Guerra dos Gibis. A formação do mercado editorial brasileiro e a censura aos quadrinhos, 1933-1964. São Paulo: Companhia das Letras, 2004.

LIMA, E. S. O discurso de uma fotografia de imprensa: uma abordagem semiótica. In: GARCIA, B. G. V. et al (org.). Análises do discurso: o diálogo entre as várias tendências na USP [e-book]. São Paulo: Paulistana, 2009. p. 199-220.

LIMA, E. S. (Multi)letramentos na escola: proposições da semiótica discursiva à ação didática. Revista do GEL, v. 16, n. 3, 2019. p. 165-190.

LIMA, E. S. 2021a. Semiótica discursiva e Educação básica: um diálogo possível e necessário. Estudos Semióticos, vol. 17, n. 1, 2021a. p. 13-36.

LIMA, E. S. Da análise linguística à análise semiótica: novos desafios ao ensino de língua materna. In: TARDELLI-ABREU, L.; GARCIA, T. S.; FERREIRA, A. de A. O. (orgs.). Pesquisas em linguagem: diálogos com a contemporaneidade [e-book]. São Paulo: Pontes, 2021b. p. 154-176.

MANCINI, R. A tradução enquanto processo. Cadernos de Tradução, vol. 40, n. 3. Florianópolis, 2020. p. 14-33.

MANCINI, R. Os modos de engajamento do leitor de Grande sertão: veredas em quadrinhos. Todas as Letras, vol. 21, n. 1. São Paulo: Mackenzie, 2019. p. 100-113.

MARCUSCHI, L. A. Produção textual, análise de gêneros e compreensão. São Paulo: Parábola, 2008.

POSTEMA, B. Estrutura narrativa nos quadrinhos. Construindo sentido a partir de fragmentos. Trad. Gisele Rosa. São Paulo: Peirópolis, 2018. 
RODRIGUES, V. O caminho da intertextualidade na leitura dos quadrinhos. $9^{a}$ Arte, vol. 3, n. 2. São Paulo: USP, 2014. p. 105-123.

ROJO, R. Letramentos múltiplos, escola e inclusão social. São Paulo: Parábola, 2009.

ROSA, R.; JAF, I. Dom Casmurro. SP: Ática (Clássicos brasileiros em HQ), 2012.

SANTOS, B. C. A.; RAMOS, P. Imprecisões sobre os quadrinhos na Base Nacional Comum Curricular. Revista Intersaberes, vol. 15, n. 36. Centro Cultural UNINTER, 2020. p. 891-912.

SILVA, Y. D. A tira cômica no livro didático de Língua Portuguesa e no Caderno de Apoio da Prefeitura de São Paulo. Dissertação de Mestrado. 220Fls. Programa de Pós-Graduação em Letras, UNIFESP. Guarulhos, 2016.

TEIXEIRA, L. Entre dispersão e acúmulo: para uma metodologia de análise de textos sincréticos. Gragoatá, vol. 9, n. 16, 2004. p. 229-242.

VERGUEIRO, W. Prefácio à edição brasileira. In: POSTEMA, Barbara. Estrutura narrativa nos quadrinhos. São Paulo: Peirópolis, 2018. p. 5-7.

VERGUEIRO, W.; RAMOS, P. Quadrinhos na educação: da rejeição à prática. São Paulo: Contexto, 2009.

YAMAGUTI, V. A efetivação dos quadrinhos no PNBE (2006-2014): da caixa ao leitor. Dissertação de Mestrado. 223Fls. Programa de Pós-Graduação em Letras, UNIFESP. Guarulhos, 2018. 